\title{
PUBLIC PARTICIPATION IN ENVIRONMENTAL IMPACT ASSESSMENT (EIA): A CRITICAL ANALYSIS
}

\author{
Ejikeme Johnson Kanu ${ }^{1}$, Emmanuel Terese Tyonum ${ }^{2}$, Smart Ndubuisi Uchegbu ${ }^{3}$ \\ 1,3 Department of Urban and Regional Planning, University of Nigeria, Enugu Campus, Nsukka Road, 410001, Nsukka, \\ Nigeria
}

${ }^{2}$ Department of Urban and Regional Planning, Benue State Polytechnic, 45 Kilometers along Otukpo - Enugu Road, Ugbokolo Benue, Nigeria

${ }^{1}$ ejikeme.kanu@unn.edu.ng, ${ }^{2}$ tyonumemmanuel@gmail.com, ${ }^{3}$ smart.uchegbu@unn.edu.ng

\section{Abstract}

This paper aims at analyzing public participation in Environmental Impact Assessment. It x-rayed the various objectives of public participation in EIA, the prospects and challenges of public participation with a view to making worthwhile recommendation necessary for better public participation in the EIA process.

The paper argue that greater attention to public participation during the EIA process leads to better environmental assessment, and thus to the formulation of projects that deliver more social benefits, fewer environmental costs and greater economic and financial benefits.

It however opined that such participation should be early in other to tap the knowledge of the general public thereby generating additional benefits to the investor in terms of cutting costs, reducing risks and preserving good reputation within the affected community.

\section{Keywords}

Public, participation, Environment, Impact, Assessment.

\section{Introduction}

There is no doubt that public involvement is a fundamental principle of the EIA process. No wonder why principle 10 of the Declaration of the United Nations Conference on Environment and Development (1992) emphasizes that environmental issues are best handled with the participation of all concerned citizens, at all the relevant level.

To be more precise, item 23.2 of Agenda 21 as adopted by United Nations Conference on Environment and Development recognized the important role of public participation in environmental impact assessment (EIA) in achieving sustainable development.

Keeping faith with the aforementioned principle and also in view of the increasing effects that development project has on the environment and public life globally, has necessitated the concept of public participation not only to effectively engage the general public, but also to establish a more mutually beneficial government and citizen relationship before, during and after any development.

Moreover, several research in the developed and developing world including world bank has shown that public involvement is a valuable source of information on key impacts, potential mitigation measures and the identification and selection of alternatives in the EIA process should it be timely, well planned and appropriately implemented.

The World Bank has found that public participation in EIA tends to improve project design, environmental soundness and social acceptability (Mutemba, 1996). Mwalyosi and Hughes (1998) identified a similar experience in Tanzania as they found out that EIAs that successfully involved a broad range of stakeholders tended to lead to more influential environmental assessment processes and, consequently, to development that delivered more environmental and social benefits.

\section{Concept of Public Participation in EIA}

Many authors have defined the concept of public participation in EIA (Umeh, Uchegbu, 1997; Tom, 2008; IAPP, 2007) Public participation in EIA variously referred to as public involvement, citizen involvement community involvement, stakeholder involvement or citizen participation is an attempt to involve the various publics in the decision making process so that a wider 
acceptability and support for the particular action can be obtained (Umeh and Uchegbu, 1997).

Public participation is the process by which an organization consults with interested or affected individuals, organizations, and government entities before making a decision.

In fact, it is two-way communication and collaborative problem solving with the goal of achieving better and more acceptable decisions. Tom (2008) defined public participation as the deliberative process by which interested or affected citizens, civil society organizations, and government actors are involved in policy-making before a political decision is taken.

International Association for Public Participation (2007) defined Public participation as the process by which an organization consults with interested or affected individuals, organizations, and government entities before making a decision (http://www.iapp.org). Public participation is two-way communication and collaborative problem solving with the goal of achieving better and more acceptable decisions.

In some countries public participation has become a central principle of public policy making. In the UK for instance, it has been observed that all levels of government have started to build citizen and stakeholder engagement into their policy-making processes.

This comes in the form of large-scale consultations, focus group research, online discussion forums, or deliberative citizens' juries.

Public participation may also be used to measure attainable objectives, evaluate impact, and identify lessons for future practice. In the USA public participation in administrative rulemaking refers to the process by which proposed rules are subject to public comment for a specified period of time (Dannenmaier, 2002).

Public participation is typically mandatory for rules promulgated by executive agencies of the US government. In Nigeria the EIA decree no 86 of 1992 brought to the fore the importance of public participation in EIA. It sees public participation as the process by which an organization consults with interested or affected individuals, organizations, and government entities before making a decision.

This practice prevents or minimizes disputes by creating a process for resolving issues before they become polarized.

One common premise of these arrayed definition of the concept of public participation is that it is a twoway communication and collaborative problem solving process by which an organization consults with interested or affected individuals, organizations, and government entities before making a decision in other to ensure that the goal of the project is achieved and also very acceptable.

\section{Objectives of public participation in EIA}

A number of reasons are adduced for the involvement of the public in EIA. Jones and Wells (2007) suggests that public participation in EIA has a critical role to play in helping to integrate economic, social and environmental objectives, i.e. move towards more sustainable development by acting as a device to strengthen and increase public awareness of the delicate balance between economic and environmental trade-offs.

Wasserman (2012) identified the objectives of public participation to include obtaining relevant information, better decisions, building understanding and legitimizing the process which will often results in creative solutions, useful role in monitoring follow up, minimizing cost and delay from unresolved conflicts in other to facilitates project implementation.

The general objectives of involving the public at different stages of the EIA process were considered by a European Commission research project (2003) as given in the table below:

Table 1. EIA stage and Objectives of public participation (European Commission, 2003)

\begin{tabular}{|l|l|}
\hline \multicolumn{1}{|c|}{ EIA stage } & \multicolumn{1}{|c|}{ Objectives of public participation } \\
\hline Screening & $\begin{array}{l}\text { Identification of significant impacts; } \\
\text { Identification of public's interest and } \\
\text { values; } \\
\text { Identification of priorities for assessment; } \\
\text { Encouraging public understanding of the } \\
\text { proposed project. }\end{array}$ \\
\hline Scoping & $\begin{array}{l}\text { The public can contribute local knowledge } \\
\text { and values to the prediction, evaluation } \\
\text { and mitigation of impacts }\end{array}$ \\
\hline Assessment & $\begin{array}{l}\text { Improvement in quality and acceptability } \\
\text { of ElA report }\end{array}$ \\
\hline EIA Report & $\begin{array}{l}\text { Public contribute to evaluation of quality } \\
\text { and acceptability of report }\end{array}$ \\
\hline Deview & $\begin{array}{l}\text { Public comment on acceptability of proj- } \\
\text { ect impacts }\end{array}$ \\
\hline Monitoring & $\begin{array}{l}\text { Public evaluate impacts that occur and } \\
\text { support project environmental manage- } \\
\text { ment process }\end{array}$ \\
\hline
\end{tabular}

Public participation is necessary for minimizing or avoiding public controversy, confrontation and delay, and can make a positive contribution to the EIA process. Umeh and Uchegbu (1997) opined that the main aim of public participation in environmental decision making is to promote productive use of inputs from private citizens and public interest groups in order to improve the quality of the environment.

They also identified the objectives as:

1 to educate the citizenry on what environmental impact assessment is all about and to disseminate information on the findings and data on potential environmental impact.

2 to identify problems, needs and values related to the determination of the environmental resources important to various segments of the public in the area and also to define areas of environmental problems and needs and to address the issues of potential solutions. 
3 to identify alternatives that may not have been considered in normal planning process and enumerate mitigating measures for various alternatives so as to minimize adverse effects.

4 to probe public perception of the actions and resources interrelations and to assess the significance of various types of impacts

5 to evaluate the alternatives which will make information about the significance of un-quantified and quantified environmental amenities available

6 to resolve existing conflicts over the proposed action through mediation of differences among various interest groups, or reaching a consensus opinion on the preferred actions.

\section{Methodology}

This paper adopted the survey design approach in its method of study. The paper is qualitative in nature. It discusses the concept of public participation in EIA, objectives of public participation in EIA, rationale for public participation and the legal basis for public participation. Also it did a comparative analysis of public participation in the developed and developing nations and the challenges of public participation. It equally proffered solutions to the challenges of public participation.

\section{Rationale for public participation}

Wasserman (2012) opined that the rationale for public participation is to enable all parties to have better understanding of the views and positions of the other. Public participation provides a means for government entity to gather the most diverse collection of options, perspectives, and values from the broadest spectrum of the public allowing (government agency) to make better and more informed decisions (World Resources Institute, 2002). According to Nwafor (2006) the rationale for public participation in EIA rest on the need to ensure that mitigation of conflicts exists, increase transparency to decisions reached, and increase in the possibility of acceptance of the project. In addition, public participation benefits stakeholders by creating an opportunity to provide comments and influence decisions.

Ebisemiju (1993) gave three main rationales for advocating genuine participation in government decision: firstly that it is the fairest system of government, secondly that it is important to the well-being of participants and thirdly that it leads to better decisions. The first argument rests on the idea that those who will be affected by decisions should have a right to influence those decisions. She points out that it can also be argued that those who bear the costs of these decisions should have the sole right to determine them.

Another reason to improve participatory processes, as outlined by Ebisemiju, is that they give dignity to those involved and affected, they help in the development of individual capability and awareness and help to create a well informed, responsive, involved citizenry. Finally one could see increased participation as an aid to policy makers who would have more information about what services were required, the limits of public tolerance, and various other forms of feedback.

Having gone through this various contributions by different authors on the rationale for public participation in Environmental Impact Assessment including that of IAPP (2008) and ODA (1996), one can easily summarize the rationales for public participation as follows:

- representation: this ensures that representative democracy is effective in allowing citizen's views to directly influence technological and development decisions in the EIA process;

- increases accountability: public participation can contribute to an accounting of the social, economic, and environmental impacts in the EIA process and of how the costs and benefits will affect different segments of society. Therefore, public participation helps to ensure that proponents and governments are accountable for their actions and responsive to public interests;

- improves process quality: public participation in EIA process provides decision makers with alternatives and ensures that decisions and policies are more robust before being approved;

- manages social conflicts: public participation can alleviate social conflicts, by bringing different stakeholders and interest groups to the same table for discussion;

- enhances process legitimacy: meaningful public participation in environmental impact assessment will help to legitimize the EIA process as provided in Agenda 21;

- environment and sustainable development: public participation has come to be seen as a vital part of addressing environmental problems and bringing about sustainable development;

- right to freedom of information: laws regarding public participation often deal with the issue of the right to know, access of information and freedom of information. In some jurisdictions the right to public participation is enshrined by law;

- source of alternatives: since the public can be a source of information and knowledge, it follows therefore that it can help to identify alternatives.

\section{Legal basis for public participation}

The legal basis for public participation in EIA is as old as EIA itself. This is because the law that established EIA also provided for public participation in the EIA process. The United State of America EPA and Public Participation Statute regulate the public's right to access relevant environmental information and to participate in the EIA procedure.

This implies participation from the early phases of the Project (screening and scoping phases). After being properly notified the public has the right to public inspection of the EIA study and participation in the public hearings the aim of which is to share views and file suggestions. 
It is important to mention that practically in all national systems of EIA there are mandatory provisions for public participation. In addition, several conventions and treaties to which different countries belongs recognizes the importance of public participation in EIA. For instance the Rio Declaration of 1992 enshrines public participation in its 27 principles. Principle 10 states that environmental issues are best handled with participation of all concerned citizens, at the relevant level.

Furthermore, Chapter 23 of the Agenda 21 recognized the need for individuals, groups and organizations to participate in environmental impact assessment procedures and to know about and participate in (pertinent) decisions. Again, whereas, Article 21 of the Universal Declaration of Human Rights provided the basic right to participation, the 1993 World Conference on Human Rights adopted the Vienna Declaration which emphasized that participatory democracy, development and respect for human rights and fundamental freedoms are interdependent and mutually reinforcing.

The content of 1994 UNECE Convention on Access to Information, Participation in Decision Making and Access to Justice in Environmental Matters, also known as the Aarhus Convention provided for public participation in EIA https://www.unece.org/fileadmin/DAM/env/pp/ documents/cep43e.pdf). For want of time and space, let me summarize by saying that there is hardly any EIA Act or Decree of any country that does not make mandatory requirements for public participation in EIA.

\section{Comparative analysis of public participation in the developed and developing nations}

Mwalyosi and Hughes (1998) reviewed over 30 EIA processes in Tanzania. They found that only two incorporated a structured approach to public involvement as part of the EIA study and, in both cases, the level of involvement was 'consultative' rather than 'participatory'. An Africa-wide review by the World Bank of 26 EIAs conducted between 1992 and 1994 found that in 12 of 14 examples reviewed, the EIA team merely informed affected groups of what they were going to do (Mutemba, 1995).

An earlier study of 35 World Bank-supported projects in Africa, found that only ten had included some measure of public involvement, and only four of these met with the World Bank's operational requirements (Cook and Donnelly-Roark, 1992). Nwafor (2009) opined that the trend is not different in Nigeria and in most African countries of the world after series of research in the EIA work done in Nigeria and Africa as a whole.

However, in the developed world, public participation is seen as a cornerstone of responsible democratic governance and a fundamental prerequisite to achieve sustainable development.

Hence, public participation is regarded as one potential solution to the crisis in public trust and governance, particularly in the Europe and America, and other developed democracies (Lerner, 2003). The idea is that public should be involved fully in the policy process in that authorities seek public views and participation, instead of treating the public as simply passive recipients of policy decisions.

Bastidas (2004) affirmed that in the developed world, democratic governance will be meaningless if governments do not ensure an effective and fully informed public participation in decision-making, in particular, in environmental impact assessment of any project.

\section{Challenges of public participation}

Wasserman (2012) opined that the main challenge of public participation is that each affected interest or public may have a different preferred or effective means of communication such as language issues, representation issues, and access to Communications technology which could hinder progress on the EIA. However, World Bank (1991) gave more embracing challenges of public participation in the EIA process as analyzed below:

- Time: The public view their involvement in EIA as unnecessary time consuming as to incur an immediate cost in terms of time and sometimes money.

- Language and public presentation: The lack of key materials in local language versions constitutes a major communication barrier to the involvement of public in EIA process.

- Education: Low levels of education, and the technical nature of many development related issues, can be a major barrier to effective participation in EIA.

- Cultural differences: Communication barrier may arise by involving the public in EIA process due to cultural believe and the traditional norms of the people.

- Gender: Gender issues, particularly to the lower status accorded to women in decision-making in many parts of the world is a major barrier to effective public participation.

- Physical remoteness: Reaching small, diverse and scattered groups in remote areas could make it is difficult for the inhabitants of such areas to participate fully in the EIA process.

- Political and institutional culture of decision making: In some cases, public involvement is perceived as a threat to authority and is viewed defensively by government agencies.

- Pressures imposed by the project cycle: Additional time and money are required during planning to achieve higher levels of stakeholder involvement.

- Mistrust: Sometimes, proponents view EIA as a necessary evil and this makes them limit the involvement of the public in the project design and implementation stage.

\section{Solutions to the challenges of public} participation

World Bank (1993) and Tom (2008) identified useful solutions to the challenges as follows: 
1. Promote active and representative participation toward enabling all community members to meaningfully influence the decisions that affect their lives.

2. Engaging the community members in understanding community issues, the economic, social, environmental, politics and psychological impacts associated with alternative courses of action.

3. Incorporate the diverse interests and cultures of the community in the EIA development process and avoiding effort that will adversely affect members of the community.

4. Work actively to enhance the leadership capacity of community members, leaders, and groups within the community and bridging communication gaps via mass media e.g. radio etc

5 . Be open to using the full range of action strategies to work toward the long term sustainability and well being of the community.

6. Although public participation does not necessarily represent all citizens, an adequate selection process can reduce uneven representation.

7. Governments must structure a participation process where the public has the opportunity to follow-up and to know how public input will be used to inform decisionmaking processes.

8. Proactive support for stakeholder involvement in EIA including incentives for involvement especially where significant costs will be incurred is required.

\section{Conclusions}

Public participation is based on the principle that dialogue between decision-makers and the public benefits both parties. It allows the public to gain an understanding of government decisions and policies, while providing the government with input to help them design and implement a better and legitimate development process.

It is usually done to obtain relevant information, make better decisions, build understanding and legitimizing the process which will often results in creative solutions, useful role in monitoring follow up, minimizing cost and delay from unresolved conflicts in other to facilitate project implementation and thus ensure wider acceptability and support for the particular action.

In carrying out environmental impact assessment (EIA), public participation provides a means for government entity to gather the most diverse collection of options, perspectives, and values from the broadest spectrum of the public allowing (government agency) to make better and more informed decisions.

This process is backed by law as the law that established EIA also provided for public participation in the EIA process.
Regrettably in Nigeria and many other African countries, previous studies carried out found that the EIA practice negates the principles of public participation. In many occasions, public participation are not part of the process and in some cases, the EIA team merely informed affected groups of what they were going to do and not to seek their contribution.

To put it clearly, an earlier study of 35 World Banksupported projects in Africa, found that only ten had included some measure of public involvement, and only four of these met with the World Bank's operational requirements.

Although the challenges adduced for non involvement of the public include time constraint, language and public presentation barriers, educational level, cultural differences, gender, physical remoteness, political and institutional culture of decision making, pressures imposed by the project cycle and mistrust; it is our conviction that engaging the community members in understanding community issues, the economic, social, environmental, politics and psychological impacts associated with alternative courses of action before, during and after project implementation will enhance the EIA process.

This will help to incorporate the diverse interests and cultures of the community in the EIA development process and avoiding effort that will adversely affect members of the community.

In conclusion, the Nigerian and African governments must structure a participation process where the public has the opportunity to follow-up and to know how public input will be used to inform decision-making processes via proactive support for stakeholder involvement in EIA including incentives for involvement especially where significant costs will be incurred is required.

\section{Recommendations}

This paper therefore recommends that for public participation to be effective in EIA study there should be greater public participation in EIA which must have an early start during the screening and scoping process of the EIA. Again there is the need to ensure proactive support for public participation in EIA through the use of incentives for involvement especially where significant costs will be incurred for the public to take part in dialogue processes.

It is also recommended that involving different stakeholder interests in the project conception and development phase prior to the commencement of the EIA study is important if their subsequent involvement within the EIA process is to be effective. 


\section{References}

Bastidas, I.S. (2004). The Role of Public Participation in the Impact Assessment of Trade Process. Speaker paper on the Impact Assessment for Industrial Development-IAIA April 28th, Vancouver.

Cook, C.C., Donnelly-Roark, P. (1992). Public Participation in Environmental Assessments in Africa. Washington D.C.: World Bank.

Dannenmaier, E. (2002). Towards Civil Society Participation in the Americas Memoirs of the Trade and Environment Workshops in the Quito Ministerial. Available at: http://www.ceda.org.ec/documentos/memorias-ingles.pdf (accessed on: 14.12.2017)

Ebisemiju, F.S. (1993). Environmental Impact Assessment: Making It Work in Developing Countries. Journal of Environmental Management, 38 (4), pp. 247-273. DOI: 10.1006/jema.1993.1044

European Commission (2003). Environmental Impact Assessment (EIA) Directive: EIA procedure.

Jones, L., Wells, K. (2007). Strategies for academic and clinician engagement in community-participatory partnered research. JAMA, 297(4), pp.407-410. DOI:10.1001/jama.297.4.407

Lerner, J. (2003). Beyond Civil Society. Public Engagement Alternatives for Canadian Trade Policy. Toronto: Canadian Institute for Environmental Law and Policy.

Mutemba, S. (1996). Public participation in Environmental Assessment for Banks Supported Projects in sub-Saharan Africa, in Environmental Assessment in Africa: A World Bank commitment, Environmental Department. World Bank Washington DC.

Mwalyosi, R.,Hughes, R. (1998). The Performance of EIA in Tanzania: an Assessment. London: International Institute for Environment and Development,

Nwafor, C.J. (2006). Environmental impact assessment for sustainable development. The Nigerian perspective. Enugu: Environment and Development Policy Centre for Africa.

Nwafor, C.J. (2009). Environmental Impact Assessment Practice in Nigeria: Achievements and challengegs. In: Proceedings of the 16th Annual National Conference Environment and Behaviour Association of Nigeria. Nigeria: Abeokuta.

ODA (1996). Manual of Environmental Appraisal. Overseas Development Administration. Revised July 1996, p.131.

Stephenson, D. et al. (1994). Public Participation in EIA: A Review of Experience in Europe and the UK. DRAFT. Centre for Environmental Management and Planning. Edinburgh: Aberdeen University Research and Industrial Services Ltd.

Umeh, L.C., Uchegbu, N. (1997). Principles and Procedures of Environmental Impact assessment (EIA). Lagos: Computer edge publisher.

United Nation (2006). Guidance on Public Participation in Environmental Impact Assessment in a Transboundary Context. United nations publications.

Wasserman, C. (2012). Strengthening Public Participation in Environmental Management in Indonesia Training Workshop. Jakarta, Indonesia

World Bank (1993). Public Involvement in Environmental Assessment: Requirements, Opportunities and Issues. Environmental Assessment Sourcebook Update No. 5. Washington D.C. 